\title{
弾性変形を考慮した浮体による波浪制御解析 WAVE CONTROL BY A FLOATING STRUCTURE WITH ELASTIC DEFORMATION
}

\author{
加藤雅也 ${ }^{1} \cdot$ 津嶋了 $^{2} \cdot$ 小田健次 ${ }^{3} \cdot$ 濱中建一郎 ${ }^{4}$ \\ Masaya KATO, Satoru TSUSHIMA, Kenji ODA and Kenichiro HAMANAKA
'正会員 博（工） 北海道大学大学院工学研究科 環境資源工学専攻（广065-8628 札幌市北区北 13 条西 8 丁目）
2 技術士 西田鉄工株式会社 マリーナ事業部（广869-0494 熊本県宇士市松山町 4541）
${ }^{3}$ 工学修士 西田鉄工株式会社 マリーナ事業部（T104-0061 東京都中央区銀座 8丁目 9-13）
${ }^{4}$ 正会員 工博 北海道東海大学教授 海洋環境学科（T005-8601 札幌市南区南沢 5-1）

In marinas, a type of floating structure composed by joined floating units is used for a breakwater or pier. Kato et al (2001) discussed the wave control effects by such a structure in the case of normal incident waves. But generally, the incident waves propagate obliquely toward the structure. In this case, the wave force is not uniform along the structure. Therefore the structure elastically vibrate with this un-uniform force. In the present paper, we analyze the wave field and the elastic vibration of the floating structure, and discuss the wave control effects and the interaction between the wave field and the motion of structure.

Key Words : floating structure, wave control effect, elastic vibration, interaction between waves and structure

\section{1.はじめに}

マリーナ等において, 小形の矩形浮体を連結して, 浮防波堤や浮栈橋に用いることが多い. 著者らはこ れまで鉊直剥離板の付いた矩形浮体の運動と波浪制 御効果について調べてきた（加滕等，2001）。そこ で用いた浮体の支持方法は, 浮体を貫通する杭にロ 一ラ等で支持させるもので, 浮体運動は上下方向だ けと仮定できる.さらに波は構造物に直角に入射す るとしたことにより, 断面 2 次元問題として境界要 素法で解いた.

しかしながら，一般的には波は斜めにも入射する. この場合, 浮体に働く流体力は浮体の長手方向には 一様ではなくなる. そのとき連結された個々の浮体 自身の撓みは無視できるが，連結材は撓むため浮体 全体では波動運動に伴い弾性振動をする. 本研究で は, 支持方法を前回と同様の杭支持とすることによ り浮体運動を上下方向だけとし, 浮体を一様な無限 長連続梁と仮定し, 浮体の弾性振動と回りの流体運 動を同時に解く方法を示す.さらに得られた結果か ら, 浮体運動と流体運動の相互作用と波浪制御効果 について述べる.

2. 基礎方程式と境界条件
ポテンシャル流れを仮定し, 図-10ような座標を 用いる.

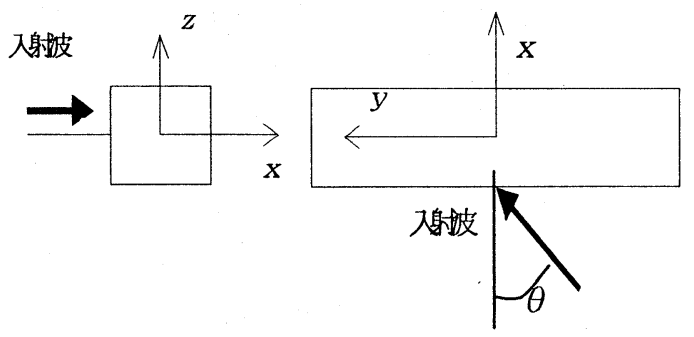

図-1 座標系

線形近似のもとで基礎方程式と境界条件は以下のよ うになる。

$$
\begin{aligned}
& \frac{\partial^{2} \Phi}{\partial x^{2}}+\frac{\partial^{2} \Phi}{\partial y^{2}}+\frac{\partial^{2} \Phi}{\partial z^{2}}=0 \\
& \frac{\partial \Phi}{\partial z}=\frac{\partial \eta}{\partial t} \quad \text { on } \quad z=0 \\
& \frac{\partial \Phi}{\partial t}+g \eta=0 \quad \text { on } \quad z=0
\end{aligned}
$$




$$
\frac{\partial \Phi}{\partial z}=0 \quad \text { on } \quad z=-h
$$

ただし， $\Phi$ は速度ポテンシャル， $\eta$ は水面変位.

$t$ は時間, $g$ は重力加速度, $h$ は水深.

さらに浮体の没水面上での運動学的境界条件として

$$
\frac{\partial \Phi}{\partial z}=\frac{\partial Z}{\partial t} \quad \text { on } \quad S_{\mathrm{B}}
$$

ただし, $\mathrm{S}_{\mathrm{B}}$ は静止時の没水面, $(X, Z)$ は浮体中 央点の座標.

力学的境界条件としては, 梁の曲げ振動の運動方程 式から

$$
m \frac{\partial^{2} Z}{\partial t^{2}}+E I \frac{\partial^{4} Z}{\partial y^{4}}=\int_{S_{B}} p_{z} d s-m g
$$

ただし, $m$ は梁の単位長さあたりの質量, $E$ は弾性 係数, $I$ は断面 2 次モーメント. $p_{z}$ は浮体に働く $z$ 方 向の流体力

\section{3. 時間的周期解と空間的周期解}

今，構造物近傍に入射する波を規則波とし，その速 度ポテンシャルを以下の様にすると，

$\Phi_{I}=a \frac{g}{\omega} \frac{\cosh k(z+h)}{\cosh k h} e^{i(\kappa x+\lambda y-\omega t)}+c . c$.

ここで $a$ は入射波振幅, $\mathbf{k}=(\kappa, \lambda)$ は波数べクト ル, c.c. は共役複素数

$\kappa=k \cos \theta \quad \lambda=k \sin \theta \quad \omega^{2}=g k \tanh k h$

波動場および浮体運動は時間的に周期的であり, 空 間的にも $y$ 方向には周期的となる.

従つて浮体近傍の速度ポテンシャルと浮体運動は

$$
\begin{aligned}
& \Phi=A(x, z) e^{i(\lambda y-\omega t)}+c . c . \\
& Z=b e^{i(\lambda y-\omega t)}+\text { c.c. }
\end{aligned}
$$

のように表すことが出来る. $b$ は浮体の振動振幅.

（3.2）と(3.3)を基礎方程式と境界条件に代入すると

$$
\begin{aligned}
& \frac{\partial^{2} A}{\partial x^{2}}+\frac{\partial^{2} A}{\partial z^{2}}-\lambda^{2} A=0 \\
& \frac{\partial A}{\partial z}-\frac{\omega^{2}}{g} A=0 \quad \text { on } \quad z=0
\end{aligned}
$$

$$
\frac{\partial A}{\partial z}=0 \quad \text { on } \quad z=-h
$$

$$
\frac{\partial A}{\partial z}=-i \omega b \quad \text { on } \quad S_{\mathrm{B}}
$$

$E I \lambda^{4} b-m \omega^{2} b=i \omega \rho \int_{S_{B}} n_{z} A d s-\rho g b \int_{S_{B}} n_{z} d s$

ただし $n_{z}$ は没水面の法線ベクトルの $z$ 成分 となり, 問題は断面 2 次元の問題に帰着する.

\section{4. 境界要素法}

3 章で得られた 2 次元問題を境界要素法を用いて解 $<$.

基礎方程式(3.4)に対する特異関数として, 零次の第 2 種変形 Bessel 関数を用いると, Green の公式から 以下の積分方程式が得られる.

すなわち得異点が領域内部のとき

$$
-2 \pi A(p)=\int_{S}\left(A \frac{\partial G}{\partial v}-G \frac{\partial A}{\partial v}\right) d s
$$

特異点が境界上のとき

$$
\begin{aligned}
& \pi A(p)=\int_{S}\left(A \frac{\partial G}{\partial v}-G \frac{\partial A}{\partial v}\right) d s \\
& G=K_{0}(\lambda r)
\end{aligned}
$$

ここで $K_{0}$ は零次の第 2 種変形 Bessel 関数, $v$ は境 界面に対する法線方向を表す， $r$ は特異点と積分点 との距離.

次に, (4.2)の積分を離散化する. 境界を微小セグメ ントに分割し積分を以下のように近似する.

$$
\begin{gathered}
\quad-\pi A_{i}=\sum_{i=1}^{N}\left(A_{j} \bar{E}_{i j}-\bar{A}_{j} E_{i j}\right) \\
\text { ここで } \bar{A}=\partial A / \partial v, \text { さらに } \\
i \neq j \text { のとき } \\
E_{i j}=\int_{\Delta s_{j}} K_{0}\left(\lambda r_{i j}\right) d s, \quad \bar{E}_{i j}=\int_{\Delta s_{j}} \frac{\partial}{\partial v} K_{0}\left(\lambda r_{i j}\right) d s \\
\quad r_{i j}=\sqrt{\left(x_{j}-x_{i}\right)^{2}+\left(z_{j}-z_{i}\right)^{2}} \\
i=j \text { のとき } \\
E_{i i}=-\Delta s_{i}\left(\log \frac{\Delta s}{2}-1\right)+(-\log \lambda+\log 2-\gamma) \Delta s_{i}
\end{gathered}
$$


$\bar{E}_{i i}=0$

没水面上の境界条件(3.7), (3.8) も同様に離散化する. 最後に境界条件(3.5)，（3.6)および入射境界で入射波， 反射波, 通過境界で通過波を与えることにより, 未 知数は水面と底面でのポテンシャル, 没水面でのポ テンシャルとその法線微分, 反射波振幅, 通過波振 幅となり連立して解ける. ただし, 特異関数として 底面対称な関数を加えたものを用いると底面での境 界条件を満たし，底面でのポテンシャルを未知数か ら除くことが出来る。なお，セグメント上の特異関 数の積分には Gauss-Legendre の数值積分により精 度を上げている.

(a)

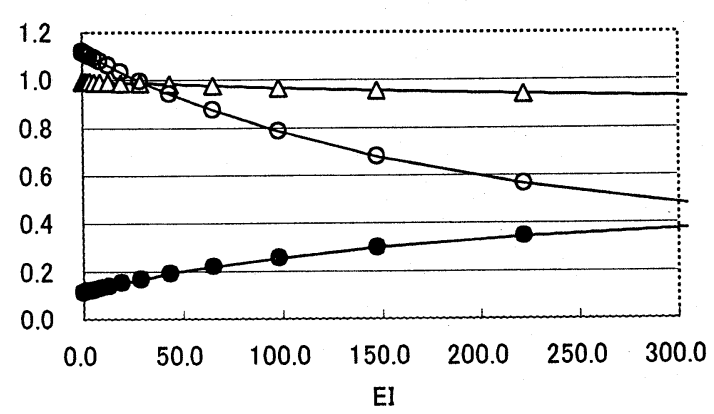

(b)

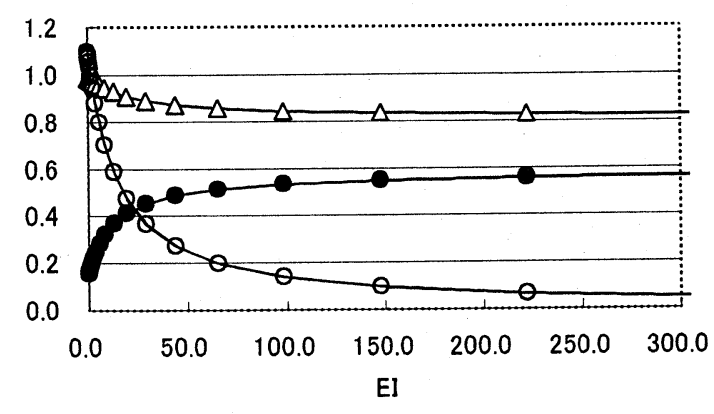

(c)

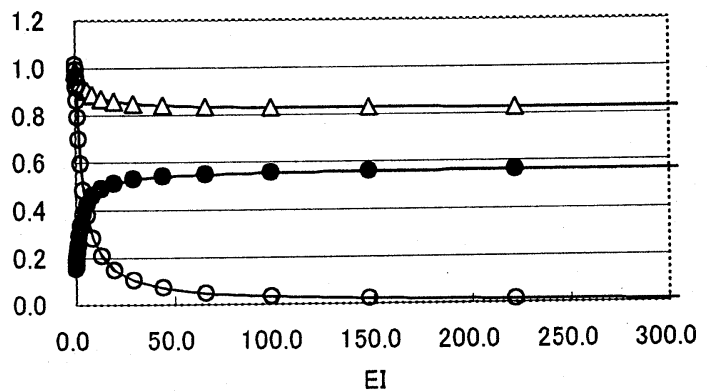

$\triangle \mathrm{AT}, \longrightarrow \mathrm{AR}, \longrightarrow \mathrm{AZ}$

$\mathrm{T}=1 \mathrm{~s}, \quad$ (a) $: \theta=10^{\circ}$ (b) : $\theta=20^{\circ} \quad$ (c) $: \theta=30^{\circ}$

図-2 EI に対する通過率, 反射率, 振動振幅

\section{5. 解析結果と考察}

計算は実験室規模を想定して, 水深 $23 \mathrm{~cm}$, 浮体 の幅 $16 \mathrm{~cm}$, 高さ $6.7 \mathrm{~cm}$, 没水深 $4 \mathrm{~cm}$ とした.
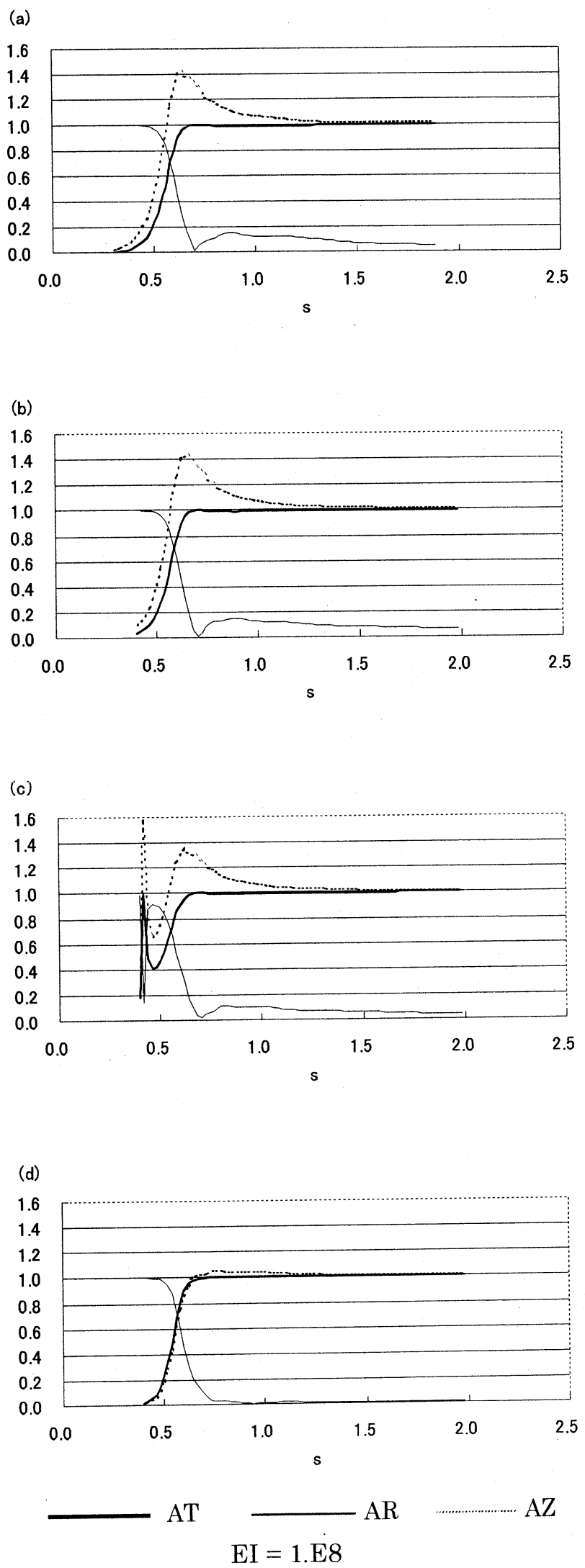

(a) : $\theta=0^{\circ}$ (b) : $\theta=10^{\circ}$ (c) : $\theta=30^{\circ}$ (d) : $\theta=50^{\circ}$ 図- 3 周期に対する通過率, 反射率, 振動振幅 
最初にはりの曲げ岡性の影響を見るため, 周期と 入射角を固定して曲げ剛性（EI）を連続的に変化さ せて通過率, 反射率, 入射振幅との比で表した梁の 振動振幅を求めたのが図-2である. 図中横軸の EI は $\rho, \mathrm{g}, \omega$ で無次元化した曲げ剛性, 縦軸の通過率 を $\mathrm{AT}$ ，反射率を $\mathrm{AR}$ ，梁の振動振幅を $\mathrm{AZ}$ で表す. 以下同様. 周期は 1 秒, 入射角は $10^{\circ}, 20^{\circ}, 30^{\circ}$ である．この図から曲げ剛性が大きくなれば歪みづ らくなり梁の振動振幅は小さくなる．またそれにつ れて反射率は大きく, 通過率は小さくなる。 入射角 が大きくなれば梁の長手方向の波長の成分が小さく なり, 梁は歪みにくくなる.したがって梁の振動振 幅は小さくなる.これらの結果は力学的に予想でき ることから解析は妥当であると考えられる.
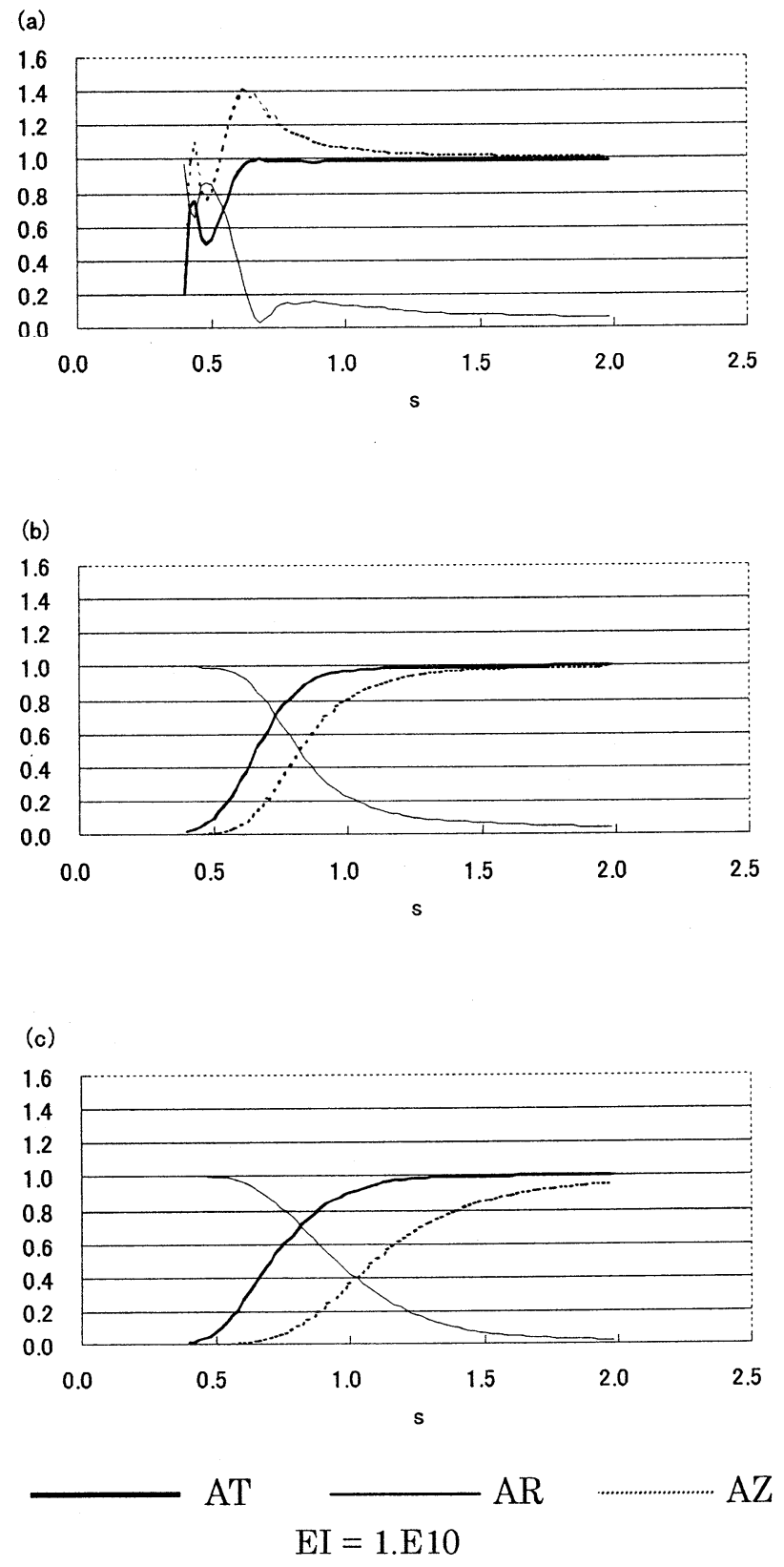
(a) : $\theta=10^{\circ}$
(b) : $\theta=30^{\circ}$
(c) : $\theta=50^{\circ}$

図-4 周期に対する通過率, 反射率, 振動振幅
次に周期の影響を見るには曲げ剛性を固定する必 要があるが, 実際の曲げ剛性を知るには，模型を用 いて測定するか，現地観測により推定しなければな らない．今回はいずれも不可能なため曲げ剛性を 種々変えて計算を行った. 図- $3,4,5$ はその一例 である。横軸は周期, 縦軸は通過率 (AT), 反射率 (AR), 振動振幅（AZ）を表す. 図-3では $\mathrm{EI}=1$. $\times 10^{8}\left[\mathrm{~g}_{\mathrm{r}} \mathrm{cm}^{3} / \mathrm{s}^{2}\right]$ (図では $1 . \mathrm{E} 8$ と表示, 以下同様), 図-4では $\mathrm{EI}=1 . \times 10^{10}\left[\mathrm{~g}_{\mathrm{r}} \mathrm{cm}^{3} / \mathrm{s}^{2}\right]$, 図-5 では $\mathrm{EI}=1$.

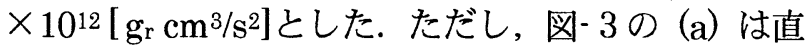
角入射の場合であるが，今回の解析方法では $\theta=0$ とすると変形 Bessel が発散し解が求められないた め加藤等（2001）の方法によった。この図から，入 射角が直角入射に近づくにつれ結果も直角入射のそ
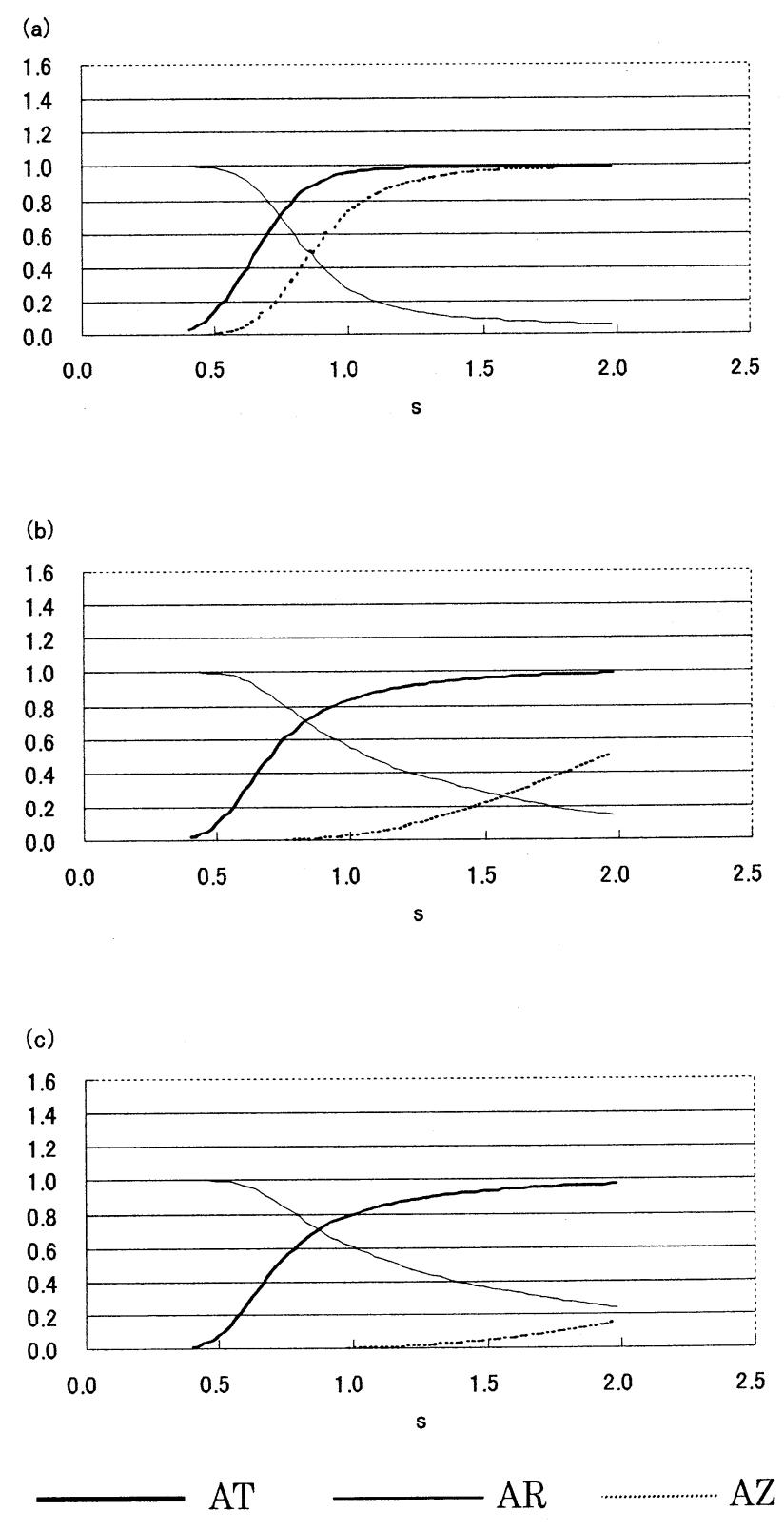
(a) : $\theta=10^{\circ}$

$\mathrm{EI}=1 \mathrm{E} 12$

図-5 周期に対する通過率, 反射率, 振動振幅 
れに近づくことが確かめられる，又，図-20結果か ら言えたことは図- $3 ， 4 ， 5$ 全体でも言えるがそれ 以外にもいくつかの特徴が見られる。ひとつは図3 の(b) と(c), 図-4の(a)の周期 6 秒近傍に見られる 振動振幅のピークである.このピークは直角入射の 場合のそれとほぼ一致する。ことから, 浮体の上下 運動と流体運動との共振によるものと考元られる.

もうひとつの特徴は図-3の(c) と図-4の(a)の周期 4 秒近傍に見られる振動振幅の急峻なピークである. このことに関しては，物理条件を変えずに計算条件 だけを変え（特に計算精度を上げるようにして）計 算した結果にも同様に現れたことから計算不安定に よるものではなく, 力学的な現象と考えられる.こ のことを確かめるため, 梁の自由振動の固有波数を 求めた. 梁の曲げ振動方程式(2.6)において右辺を 0 として,

$$
m \frac{\partial^{2} Z}{\partial t^{2}}+E I \frac{\partial^{4} Z}{\partial y^{4}}=0
$$

に対し，

$$
Z=e^{i\left(k_{r} y-\omega t\right)}
$$

を代入すると，

$$
k_{r}= \pm \sqrt{\omega} * \sqrt[4]{\frac{m}{E I}}
$$

が得られる。

図- 6 は(4.3)で得られる梁の波数と入射波の波数の $\mathrm{y}$ 成分を, 横軸を周期で表したものである. 図中太 線の $\mathrm{E} 8$ は梁の曲げ剛性を表し, $\mathrm{EI}=1 . \times 10^{8}\left[\mathrm{~g}_{\mathrm{r}}\right.$ $\left.\mathrm{cm}^{3} / \mathrm{s}^{2}\right]$ のこ, 以下同様. $\theta 10$ は入射波の入射角を 表し $\theta=10^{\circ}$ のこと, 以下同様.これによれば，E8 と $\theta 30$ の交点の周期は同じ条件の図-3の (c) とほ ぼ一致し, E10 と $\theta 10$ の交点の周期は同じ条件の図 -4 の（a）とほぼ一致している.このことから，これ らの振動振幅のピークは梁の弾性振動波と波による 流体運動の共振と考えられる. しかしながら, 今回 計算対象とした周期の範囲にはふたつの波数の一致 する個所は $\mathrm{E} 10$ と $\theta 30, \mathrm{E} 12$ と $\theta 10$ にも存在するが 同じ条件の図-4の (b) 図-5 の (c) にはピークが見ら れない.このことは，ふたつの波数が一致すること は共振を起こす必要条件であり, 十分条件ではない

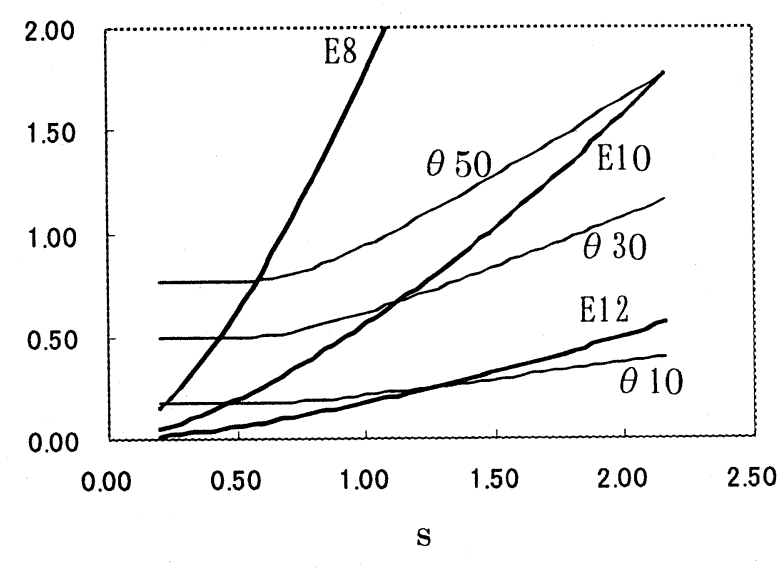

梁の波数, 波の $\mathrm{y}$ 波数

図-6 入射周期に対する波数

ことを意味し, 梁の運動が与える流体運動への影響 が梁の運動をさらに強化するか抑制するかはより詳 細に調べてみなければわからない。一方, 加藤等

（2001）の実験によれば，このような周期の変化に 伴う反射率, 通過率などの急激な変化は構造物近傍 の剥離渦やローラの摩擦などにより緩和されるため, 実際では今回対象と考えている小形の浮体構造物で も同じ効果により緩和されるものと考えられる.

最後に, 今回の解析では梁は無限長として解いた が，実際には有限長であるから入射角が直角入射に 近いと波のy方向の波長に比し梁の長さは短くなり よい近似とは言えなくなる， その場合の正確な解析 は空間 3 次元で行わなければならない. しかしなが ら，その様な場合でも，曲げ剛性が小さければ今回 の解が，曲げ剛性が大きければ直角入射の解が時間 的位相差を除き近似されると考えられる。

\section{参考文献}

加藤等 : マリーナにおける二重鈶直板付矩形浮体の 港内波制御に関する研究, 海洋開発論文集, 第 17 巻, 211-216, 2001 